\title{
Risks to human health from ammunition-derived lead in Europe
}

\author{
Rhys E. Green (1), Deborah J. Pain
}

Received: 8 February 2019/Revised: 17 April 2019/Accepted: 19 April 2019/Published online: 16 May 2019

\begin{abstract}
It has been known for centuries that lead is toxic to humans. Chronic exposure to lead, even at low levels, is associated with an elevated risk of cardiovascular and chronic kidney disease in adults and of impaired neurodevelopment and subsequent cognitive and behavioural development in the foetus and young children. Health agencies throughout the world have moved from assuming that there are tolerable levels of exposure to lead to a recognition that valid 'no-effect' thresholds cannot currently be defined. Formerly, the most important exposure pathways were occupational exposure, water from lead plumbing, paints, petrol additives and foods. Regulation of products and improved health and safety procedures at work have left dietary lead as the main remaining pathway of exposure in European countries. Ammunition-derived lead is now a significant cause of dietary lead exposure in groups of people who eat wild game meat frequently. These are mostly hunters, shoot employees and their families, but also some people who choose to eat game for ethical, health or other reasons, and their children. Extrapolation from surveys conducted in the UK and a review of studies of game consumption in other countries suggest that approximately 5 million people in the EU may be high-level consumers of lead-shot game meat and that tens of thousands of children in the EU may be consuming game contaminated with ammunitionderived lead frequently enough to cause significant effects on their cognitive development.
\end{abstract}

\section{INTRODUCTION}

Lead has a wide range of negative effects on human health and functioning. It is not required for essential biochemical functions in any animal species. Adverse effects of exposure to lead on human health occur for most body systems. Some effects occur in individuals with low concentrations of lead in the blood, indicating low levels of exposure (EFSA 2010). In this paper, we first describe the pathway by which humans are exposed to dietary lead derived from spent ammunition. This appears to depend largely upon fragmentation of lead projectiles into small particles when they hit game animals, and absorption from the intestine of dissolved lead from embedded particles when they are ingested along with game meat. We next examine the relationship between the rate at which game meat is eaten by average and high-level consumers and the effects of exposure to dietary lead on the concentration of lead in the blood $(\mathrm{B}-\mathrm{Pb})$ and the way in which that is mediated through absorption. Finally, we assess the potential magnitude of effects of dietary exposure to ammunitionderived lead on human health and functioning, the number of people in the EU who may be affected, and the consequences of these effects for society. In taking these last steps, we benefit from the many studies of the relationship between $\mathrm{B}-\mathrm{Pb}$, as a measure of exposure to lead from any source, and health outcomes, which are generally accepted to hold regardless of the source of the lead.

Keywords Bioavailability · Bullet - Gunshot · Health risk · IQ 
PATHWAYS BY WHICH HUMANS ARE EXPOSED TO AMMUNITION-DERIVED LEAD

\section{Routes by which lead is absorbed by humans and its fate in the body}

Organic forms of lead can be absorbed through the skin, but lead primarily enters the bloodstream following inhalation of contaminated dust and ingestion of contaminated material, including dust, paint fragments, food and water. Previously, lead from paint, lead plumbing and environmental residues of leaded petrol were the predominant routes of non-occupational human exposure to lead. Exposure of humans to lead from these sources has been reduced substantially by increased regulation and substitution of products that contain lead, and reduced occupational exposure through health and safety legislation and its enforcement. The removal of lead additives from vehicle fuel across Europe has resulted in a substantial decrease in lead absorbed through the lungs after inhalation from the atmosphere and by ingestion of dust. Today, most lead exposure of the general population in the EU is from the diet (EFSA 2010). The rate of absorption of ingested lead depends on the age, nutritional status and other individual characteristics and on the physical and chemical characteristics of the lead ingested. Children absorb a larger proportion of the lead they ingest lead than adults (Mushak 1998). After absorption, lead is transported around the body in the bloodstream. It is transferred from the blood to soft tissues such as the liver and kidneys and also to bone where it accumulates. Excretion of lead is via faeces and urine and by incorporation into hair, which is eventually shed. The half-life of lead in blood is about 30 days, but its half-life in bone is several decades (USASTDR 2007). Hence, long-term accumulation of lead, primarily in bone, tends to occur in individuals with regular exposure. As a consequence of accumulation, about $94 \%$ of the total lead body burden in adults is in bone, compared with about $73 \%$ in children. Lead may be mobilised from bone in times of physiological stress, resulting in elevated blood lead concentrations (USATSDR 2007).

There are several pathways by which people are exposed to ammunition-derived lead. These include (1) via water or plants and animals that have taken up lead derived from spent ammunition deposited in the environment (e.g. review of Green 2015), (2) inhalation by hunters of leadcontaining fumes from propellant or lead dust when guns are fired (discussed in Green and Pain 2015a), (3) lead mobilised from lead projectiles and fragments thereof which have been shot into the human body and retained (Weiss et al. 2017), (4) occasional retention of ingested lead projectiles in the caecum, which may cause appendicitis (Clemente et al. 2017), (5) ingestion and absorption of ammunition-derived intracellular lead incorporated into tissues in game meat, although this route is thought to be minor (Green and Pain 2015a), (6) ingestion of lead ammunition or ammunition fragments by eating meat from wild game shot with lead ammunition. In the current review, we focus on the last pathway (6), which may affect a substantial number of people.

\section{Particles of lead derived from projectiles in meat from game animals killed using lead ammunition}

It has long been known that the meat of game animals killed using lead ammunition may contain whole projectiles or large fragments of metal derived from them. However, it was supposed until recently that little of the lead from projectiles shot into game animals was eaten by human consumers because some of the projectiles and their fragments exited the body of the game animal, whilst others were removed during preparation of the meat or detected visually or in the mouth by the consumer and rejected. Because of this supposed detection and removal of almost all ammunition-derived metallic lead from ingested food, it was assumed that only small quantities were ingested and were therefore of little concern. As far as we know, these assumptions have not been made explicit, but we find it difficult otherwise to account for the absence of ingestion of meat from game shot with lead bullets and lead shot as a route of exposure to dietary lead in the Codex Alimentarius Code of Practice on reducing exposure to lead in food (Codex Alimentarius 2004). In addition, these assumptions may account for the absence of a maximum level (ML) for lead in human foodstuffs derived from wildshot game animals set in the Codex Alimentarius General Standard for Contaminants and Toxins (Codex Alimentarius 2018) and the European Union's Regulation (EC) No 1881/2006 (EC 2006). MLs were not set for lead in game meat, despite low MLs being set by both systems for many other foodstuffs, including meat from domesticated animals and many wild foodstuffs eaten much less often than meat from domesticated animals, such as cephalopods and bivalve molluscs. This absence of MLs for lead in game meat is surprising, given that various studies described in the following sections have shown that considerable quantities of lead pass into the flesh from the main body of the projectile when it impacts the body of a game animal, some of which is in the form of small particles unlikely to be detected during food preparation or by consumers.

One method of studying this topic is to measure the change in mass of bullets recovered from wild-shot game animals, compared with unfired projectiles. Stokke et al. (2017) retrieved bonded lead core, lead core and copper bullets from carcasses of moose (Alces alces). The mean metal loss per bullet on entering the body of the moose was 
$3.0 \mathrm{~g}$ (18-26\% of initial mass), $2.6 \mathrm{~g}(10-25 \%)$, and $0.5 \mathrm{~g}$ $(0-15 \%)$ for lead core, bonded lead core, and copper bullets, respectively. Based on hunting and ammunition use data for the year 2013/14, this implies the deposition of $690 \mathrm{~kg}$ of lead and $21 \mathrm{~kg}$ of copper annually in fragments smaller than the bullets in wild-shot moose carcasses in Finland, Norway and Sweden.

The most frequently used method for detecting projectile fragmentation is X-radiography. Such studies showed that mammals shot using lead bullets often contained lead fragments which were small, numerous and widely dispersed in edible soft tissues away from the wound channels. X-ray studies of red deer (Cervus elaphus) (Knott et al. 2010), roe deer (Capreolus capreolus) (Knott et al. 2010) and white-tailed deer (Odocoileus virginianus) (Hunt et al. 2009; Grund et al. 2010) killed using lead bullets revealed the presence of many small bullet fragments in the edible tissues of the carcass at distances up to $24 \mathrm{~cm}$ from the wound channel. Small fragments formed a substantial proportion of the total detected fragment mass (Knott et al. 2010), with $34 \%$ of the mass of lead in the eviscerated carcass composed of fragments of $0.01 \mathrm{~g}$ mass or smaller $(<1.19 \mathrm{~mm}$ diameter). Fragments as small as this have been found not to be completely removed by standard butchery practices used on deer in the USA (Hunt et al. 2009), with at least one bullet fragment being detected in $32 \%$ of $0.91 \mathrm{~kg}$ packages of minced meat prepared from carcasses of wild-shot deer. Such small fragments in processed meat would probably not be detected by the consumer.

Lead gunshot pellets can also fragment when they are fired into wild game such as gamebirds and waterfowl, leaving small particles detectable on X-radiographs. Small radio-dense metal fragments, identified as shards of metallic lead, were visible on X-radiographs in $76 \%$ of 121 wild-shot gamebirds of six species obtained from selected supermarkets, game dealers or game shoots in the UK (Pain et al. 2010). Most fragments were less than about a tenth of a shotgun pellet in size and many were considerably smaller. The small radio-dense particles sometimes appeared to follow the track taken by a shotgun pellet during passage through a bird, were sometimes clustered around bone, but sometimes appeared to be scattered throughout the bird's body. This study estimated that approximately $0.3 \%$ of the mass of lead in the gunshot that struck a gamebird would need to have fragmented into small particles to account for the concentrations of lead subsequently measured by chemical assays of in cooked meals prepared using the gamebird meat. Large fragments of gunshot visible to the naked eye had been removed before preparation of the meals.

Andreotti and Borghesi (2013) X-rayed 196 starlings (Sturnus vulgaris) shot in Italy and found lead gunshot pellets and/or visible metallic fragments in 118 carcasses $(60.2 \%)$. There were abundant tiny fragments embedded in the tissues that would probably be ingested by human consumers. Andreotti et al. (2016) analysed 59 carcasses of woodcock (Scolopax rusticola) shot by Italian hunters in Ukraine. $96.6 \%$ or carcasses contained ammunition residues and radiographs revealed 215 whole pellets (mean $=$ 3.64 per bird) and 125 clusters of fragments (mean $=2.14$ per bird) in 51 and 48 of the birds, respectively. Three quarters of the fragmentation centres contained small particles $(<1 \mathrm{~mm}$ diameter).

A limitation of X-radiographic studies of projectile fragmentation is that it has rather coarse resolution. When using two-dimensional $\mathrm{X}$-radiographs, it is difficult to identify images of radio-dense particles as projectile fragments if they are smaller than about $0.1 \mathrm{~mm}$, or even larger. Images of lead particles smaller than this could be confused with bone fragments. In the X-radiographic study by Knott et al. (2010) of metallic fragments in carcasses of deer shot using lead bullets, the smallest fragments identifiable unambiguously were about $0.4 \mathrm{~mm}$ in diameter. Ammunition fragments smaller than this might be present but not be detected by conventional X-radiography. A recent study found that many nanoparticles of lead much smaller than this, and of substantial total mass, were present in the meat of animals shot using lead bullets. As well as possibly causing fracture into larger particles, the kinetic energy of a bullet is partly converted, upon striking the target animal's flesh, into a permanent change in shape of the projectile and into heat. The heat may cause some of the lead to melt or vaporize (Finney et al. 2016). On cooling, very small nanoparticles of solid lead may form from the melt. Kollander et al. (2017) used inductively coupled plasma-mass spectrometry in single-particle mode (spICP-MS) on meat from wild boar (Sus scrofa) and roe deer and found large numbers of nanoparticles of lead in samples taken within $10 \mathrm{~cm}$ of the wound channel, with no nanoparticles of lead being found in game meat further from the wound channel. The diameter of detected lead nanoparticles was in the range 40 to $750 \mathrm{~nm}$ with a median diameter of around $60 \mathrm{~nm}$. Hence, the diameter of even the largest nanoparticles detected by spICP-MS was much smaller than the minimum diameter of lead particles detectable by imaging using X-radiography $(100000 \mathrm{~nm})$. Nanoparticle mass concentration within $10 \mathrm{~cm}$ of the wound channel ranged from 290 to $340 \mathrm{ng} / \mathrm{g}$ wet weight (290-340 ppb, w.w.), with nanoparticle number concentrations from 27 to 50 million particles per gram of meat. It is possible that metallic nanoparticles might be absorbed unmodified through the wall of the intestine or into epithelial cells or that their high surface:volume ratio could result in much of the nanoparticle lead being dissolved and absorbed as lead salts. The substantial gap between the largest nanoparticles 
of lead detected by spICP-MS and the smallest fragments detected by $\mathrm{X}$-radiography raises the question of whether there are also lead particles in game meat intermediate in size between those detected by the two methods. Nanoparticles of lead have only been searched for so far in game animals killed using lead bullets. Gunshot pellets seem less likely to give rise to nanoparticles of lead because of their lower impact velocity, but whether such nanoparticles are absent from animals killed using lead gunshot remains to be established.

\section{Concentrations of lead in the meat of game animals consumed by humans}

Many chemical analyses of the concentration of lead in the tissues of game animals killed using lead ammunition have been published. However, it is not always clear what the significance of these concentrations is for human health because some analyses include lead from whole gunshot and large projectile fragments present in meat samples, which would almost certainly be removed during food preparation or by the consumer (see preceding section). For example, EFSA (2010) reviewed a large number of determinations of lead concentration in game meat, but it was unclear for most of them whether whole shot and/or large projectile fragments had been removed or not. Hence, in this paper, we concentrate on recent studies in which protocols regarding removal of projectiles, large fragments and wound channel tissue were clearly defined or meat already processed for human consumption was analysed. We also summarise published reviews of the older literature.

Dobrowolska and Melosik (2008) measured lead concentrations in samples of muscle tissue from ten wild boar and ten red deer shot with lead bullets. Lead concentrations in muscle tissue were elevated above the background level at up to $30 \mathrm{~cm}$ from the bullet channel. Butchering and food preparation procedures on these boar and deer would have required that a substantial proportion of muscle be discarded if all tissue retained for human consumption was to have lead concentration within the ML set by the EU of $100 \mathrm{ppb}$ (w.w) for non-game meat (bovine animals, sheep, pig and poultry-excluding offal). Lindboe et al. (2012) found that the mean concentration of lead in random samples of ground meat from moose killed in Norway with lead-based bullets was $5600 \mathrm{ppb}$ (w.w). Danieli et al. (2012) analysed lead levels in muscle and liver taken from 54 wild boar shot in central Italy. Areas damaged by the bullet were discarded and all meat was taken from more than $40 \mathrm{~cm}$ from tissue damage or the bullet tract. Mean lead concentrations were $124 \mathrm{ppb}$ (w.w.) in muscle and $329 \mathrm{ppb}$ in liver.
Ertl et al. (2016) analysed concentrations of lead in muscle tissue from pheasants (Phasianus colchicus) and five wild mammal species shot in Austria. Gunshot pellets and wound channel tissue were excluded from the samples taken for analysis. Mean lead concentrations were $77000 \mathrm{ppb}$ (w.w.) in muscle from chamois (Rupicapra rupicapra), $9000 \mathrm{ppb}$ (w.w.) in meat from brown hares (Lepus europaeus), 125000 ppb (w.w.) in pheasant, 6 ppb (w.w.) in red deer, $140 \mathrm{ppb}$ (w.w.) in roe deer and $15 \mathrm{ppb}$ (w.w.) in wild boar. Animals killed using gunshot pellets had particularly high lead concentrations. Lehel et al. (2016) found that the mean lead concentration in muscle samples unlikely to contain large bullet fragments taken from roe deer killed in Hungary using lead bullets was 480 ppb (w.w.). Vogt and Tysnes (2015) collected a sample of packs of minced meat from wild-shot moose from 27 groceries in southern Norway. The mean lead concentration was $1790 \mathrm{ppb}$ (w.w.). Only $27 \%$ of packs had a lead concentration below 100 ppb (w.w.), the EU's ML for nongame meats.

Johansen et al. (2004) found that lead contamination of the meat of seabirds killed using lead shot occurred even though shot was removed after cooking. Pain et al. (2010) found a mean lead concentration of $1181 \mathrm{ppb}$ (w.w) in meals prepared from 121 wild-shot UK gamebirds of six species, from which shot and large fragments had been removed prior to meal preparation and analysis, with no significant variation among species. Lead concentrations in the meals were correlated with the number of shotgun pellets and large fragments of lead removed before chemical analysis but also, after this effect was allowed for statistically, with the number of small radio-dense fragments detected by X-radiography. These small fragments could not easily have been removed. High concentrations of lead occurred in some meals prepared from birds in which no whole pellets or large fragments at all were apparent on X-rays. The only plausible mechanism for this observation is that lead particles remained in the meat after the removal of whole shot and large fragments, conforming to usual culinary practice. McAuley et al. (2018) reported lead concentrations in meat from grouse (Bonasa and Falcipennis sp.) killed in Canada using lead ammunition (mostly shotgun pellets). Pellets and projectile fragments were removed prior to analysis. Grouse breasts (two per bird) were categorised as having visible signs of shot impacts on the exterior or not and the two classes were analysed separately. The mean concentration of lead in impacted breast muscle was 968 ppb (w.w.), with the concentration in non-impacted breasts being $13 \mathrm{ppb}$ (w.w.).

The results presented above show that mean lead concentrations in the meat of wild game mammals and birds shot with lead ammunition and eaten by humans are often one or two orders of magnitude higher than the non-game 
meat ML of $100 \mathrm{ppb}$ (w.w.) set by the European Commission, even when projectiles, large fragments and wound channel tissues were discarded. In the next section, we examine evidence that lead present in ingested game meat is absorbed, resulting in consumers having higher $\mathrm{B}-\mathrm{Pb}$ than would otherwise be the case.

\section{Potential effects of improved meat preparation practices on concentrations of lead in the meat of game animals}

Several examples are given in the previous section of normal food preparation methods leaving elevated concentrations of lead in the meat of large game animals and gamebirds. This section examines the practicality of decreasing lead concentrations in meat consumed by humans by more stringent butchery practices. Lead concentrations in the meat of large game animals are usually much higher within $30 \mathrm{~cm}$ of the wound channel than further away (e.g. Dobrowolska and Melosik 2008). Butchering to remove meat within a $30 \mathrm{~cm}$ radius around the wound channel left by a lead bullet would, therefore, be expected to remove much of the ammunition-derived lead, but it is not a usual practice to discard such a large proportion of meat because this is seen to be wasting a large amount of food. For small game, such as gamebirds, it would be impractical to remove all of the meat potentially contaminated with lead from gunshot as multiple gunshot usually enter a small game animal and fragments can be widely dispersed (Pain et al. 2010). The same difficulty arises for the preparation of meat from wild-shot brown hares (Stankevičiūtè et al. 2013). Kollander et al. (2014), reported a study of enhanced meat preparation in which twenty crows (Corvus corone) were shot, ten with each of two shot types: a sports shooting shot sometimes used for small game, and a standard small game shooting shot. Breast muscle was removed, damaged tissue separated and shot removed prior to analysis. The sports shooting shot type resulted in mean tissue lead levels almost 400 times the EU ML before cleaning, falling to 14 times the EU ML after cleaning. The game shooting shot type resulted in mean tissue $\mathrm{Pb}$ levels 1840 times the EU ML before cleaning (as one shot remained in a sample; 1.8 times the EU ML of $100 \mathrm{ppb}$ excluding this sample), dropping to the EU ML, following cleaning. This small study shows that, even with careful butchering, mean lead levels following cleaning did not drop below the EU ML for other meats. In addition, crows are different in structure and size from gamebirds and waterfowl and are not widely eaten by humans. Hence, they may not be an appropriate model species for a study of the effects of meat preparation methods for small game in general. A study of 121 gamebirds from the UK found mean lead concentrations in edible meat of $1181 \mathrm{ppb}$ (12 times the EU ML) after whole shot or large (visible) fragments had been removed, being some 6.6 times higher than that of the 9 crows (if the outlier containing a shot is excluded) in the Kollander et al. (2014) study. Of the five bird species surveyed by Pain et al. (2010) that could legally be shot with lead in the UK, the lowest mean concentration of lead found in meals prepared from the meat was $433 \mathrm{ppb}$ for woodpigeon (Columba palumbus). This lowest mean still greatly exceeds (by a factor of 2.4 times) the lead concentration in meat in the crows shot with typical game shooting ammunition, before cleaning (Kollander et al. 2014).

Strict protocols to dispose of the damaged meat removed by enhanced butchery and prevent it from entering the human food chain would need to be established if consumers were to be confident that it would not be incorporated into other products destined for human consumption, such as game sausages or minced meat, or included in food for other animals, such as domestic dogs. We conclude that lead concentrations in game meat eaten by humans could be reduced by discarding a higher proportion of meat from carcasses than is the current usual practice, but the amounts required to be discarded might be substantial and make practical implementation difficult to achieve and verify, especially for small game animals.

\section{Bioavailability of ammunition-derived lead present in game meat and the effect of its ingestion on the blood lead concentration of consumers}

We know of no experimental studies of humans to measure the bioavailability of dietary lead derived specifically from ingested ammunition residues. However, Hunt et al. (2009) fed domesticated pigs (Sus scrofa domesticus) on two meals, separated by 1 day, of minced meat from deer shot with lead-based bullets, which was known from X-radiography to contain small bullet fragments. The pigs' $\mathrm{B}-\mathrm{Pb}$ was then measured and compared with that of controls fed on deer meat that contained no fragments. Two days after first ingestion of fragment-containing venison, mean $\mathrm{B}-\mathrm{Pb}$ of the treated pigs peaked at $2.29 \mu \mathrm{g} / \mathrm{dL}$, which was 3.6 times higher than that of controls $(0.63 \mu \mathrm{g} / \mathrm{dL})$. B-Pb levels in the experimental pigs returned to being similar to those of controls within 6 days of the last ingestion of contaminated meat. Isotope ratios of lead in the meat matched those of the lead in the bullets used to shoot the deer, supporting the contention that the absorption by the pigs was of dietary lead derived from the ammunition. The quantity of ammunition-derived lead ingested by the pigs was not measured, so this experiment showed that ammunition-derived dietary lead is bioavailable to pigs, but did not measure its absolute bioavailability. 
Several comparative studies indicate that the $\mathrm{B}-\mathrm{Pb}$ of people who eat game animals killed using lead ammunition is elevated compared to that of people who do not consume game meat and some of these show that the degree of elevation of $\mathrm{B}-\mathrm{Pb}$ is related to the amount of game meat eaten. These studies indicate that some ingested ammunition-derived lead is absorbed (Dewailly et al. 2001; Bjerregaard et al. 2004; Johansen et al. 2006; Iqbal et al. 2009; Bjermo et al. 2013; Meltzer et al. 2013; Knutsen et al. 2015). In addition, analysis of stable isotope ratios of lead in blood samples indicates that exposure to ammunitionderived lead is the main cause of elevated blood lead (B$\mathrm{Pb}$ ) in indigenous people in Canada (Tsuji et al. 2008). Knutsen et al. (2015) reviewed several studies of the effect of game meat consumption on B-Pb including: (1) a 2012 assessment by the Norwegian Scientific Committee for Food Safety (VKM) of lead exposure from cervid meat to the Norwegian population and (2) a Norwegian Institute of Public Health investigation of associations between cervid meat consumption and $\mathrm{B}-\mathrm{Pb}$ in Norwegians (the Norwegian Game and Lead study). There was an increase of approximately $31 \%$ in blood lead concentration associated with cervid game meat consumption once a month or more, mostly associated with consumption of minced cervid meat. A few studies have reported no significant effect of eating game meat on $\mathrm{B}-\mathrm{Pb}$, but they have significant weaknesses. Haldimann et al. (2002) did not find elevation of $\mathrm{B}-\mathrm{Pb}$ associated with intake of lead from game meat when they compared $\mathrm{B}-\mathrm{Pb}$ of 31 hunters with that of 42 controls. However, no information was available for the anonymous control group beyond age and sex. Whether or not they were active hunters, their level of game consumption and other variables that might affect exposure to lead were unknown. In addition, the effects of potentially confounding variables, such as drinking and smoking habits, did not appear to have been taken into account in the statistical analysis. With this small sample size and the lack of adequate controls we, therefore, consider a conclusion of no effect to be unreliable. Fustinoni et al. (2017) measured $\mathrm{B}-\mathrm{Pb}$ in 70 consumers of game meat and 25 controls and concluded that game meat consumers did not have higher levels of $\mathrm{B}-\mathrm{Pb}$ when other variables, namely hunting and wine drinking, were taken into account statistically. Mean $\mathrm{B}-\mathrm{Pb}$ was about twice as high for game meat consumers as it was for non-consumers, but the authors argued that this was because of confounding effects of the other variables. We consider this conclusion to be unreliable because people who had consumed game within the week before sampling were excluded from the study. Given the experimental finding of Hunt et al. (2009) that the elevated $\mathrm{B}-\mathrm{Pb}$ of pigs fed on ammunition-derived lead had returned to normal within 6 days of last eating contaminated meat, this exclusion would probably bias the measured $\mathrm{B}-\mathrm{Pb}$ of frequent game meat consumers to be lower than their usual level, as well as excluding some high-level, very frequent consumers of game from the study. In addition, the 'frequency of hunting' variable included in the multiple regression analysis was positively correlated with the 'game meat consumption' variable. This correlation between explanatory variables makes conclusions about the relative importance of the two variables problematic.

Taken together, the findings summarised above indicate that $\mathrm{B}-\mathrm{Pb}$ of humans tends to increase in association with consumption of game meat containing ammunition-derived lead due to absorption of ammunition-derived lead from the alimentary canal, as was demonstrated experimentally for pigs by Hunt et al. (2009). However, without further analysis, these observations do not indicate what proportion of the ammunition-derived lead ingested is absorbed or how much $\mathrm{B}-\mathrm{Pb}$ is increased per unit of dietary lead ingested. In the absence of experimental data, such estimates require correlational studies in which both the intake of lead and the elevation of $\mathrm{B}-\mathrm{Pb}$ are measured.

Green and Pain (2012) used observations from two studies of Greenland adults (Bjerregaard et al. 2004; Johansen et al. 2004, 2006) to derive a quantitative empirical relationship by linear regression modelling between the mean daily intake of dietary lead from the meat of birds killed using lead shot and the mean concentration of $\mathrm{B}-\mathrm{Pb}$. There was a strong relationship in the data from both Greenland studies between mean $\mathrm{B}-\mathrm{Pb}$ and the estimated mean rate of intake of dietary lead from meals of cooked wild bird meat. The regression models of Green and Pain (2012) indicated that the effect of ingested ammunition-derived lead on $\mathrm{B}-\mathrm{Pb}$ was $39 \%$ lower than that expected for lead not derived from ammunition (Carlisle and Wade 1992). The absolute bioavailability of dietary lead derived from ammunition (the proportion of the ingested amount which is absorbed and enters the blood) might be expected to be lower than that of lead in the general diet because some of the ingested ammunition lead may remain as metallic fragments after cooking and processing in the alimentary tract. Metallic lead, especially that remaining in large fragments, may not be totally dissolved nor be absorbed in the intestine as readily as more soluble lead salts and complexes (Barltrop and Meek 1975; Oomen et al. 2003). However, it should also be noted that this regression method is subject to a well-known bias. Least squares regression assumes that the independent variable (in this case the dietary lead intake rate) is known without error. This is not the case because the intake rate means used were determined from sample estimates with attached errors which cannot be fully quantified and adjusted for. The direction of this bias on the slope of the fitted regression is negative, meaning that the true absolute 
bioavailability of lead may be larger than that estimated by this method.

There appear to be no published studies in which $\mathrm{B}-\mathrm{Pb}$ was related to ingestion rates of ammunition-derived lead in children. The bioavailability of lead in the ordinary diet is considerably higher in children than in adults (Mushak 1998; IEUBK 2010). Green and Pain (2012) assumed that the ratio of the absolute bioavailability of dietary lead from cooked wild bird meat to that of lead from the ordinary diet, calculated for adults (above), would be the same in children. As there is a widely used value for the absolute bioavailability to children of lead from the ordinary diet (0.5, from Mushak 1998; IEUBK 2010), they estimated a value for absolute bioavailability in children of dietary lead derived from the cooked meat of wild birds of 0.3060 . The same caveat about probable negative bias in this estimate applies as that described above for adults.

We conclude that a considerable proportion of the ammunition-derived lead present in food ingested by consumers is absorbed into their blood and that this results in elevated $\mathrm{B}-\mathrm{Pb}$ of game consumers, probably for a period of days after ingestion. This lead then moves into other tissues or is excreted.

\section{EFFECTS OF LEAD ON HUMAN HEALTH AND FUNCTIONING}

\section{Principal effects of lead on human health}

Once lead has been absorbed into the body, its effects on health and functioning are thought to be independent of its original source. Hence, correlations between health outcomes and concentration of lead in tissues are an important source of information on effects of lead on health. The concentration of lead in whole blood $(\mathrm{B}-\mathrm{Pb})$ is the most widely used measure of recent exposure, because of the short half-life of lead in the blood. Although measurements of lead concentrations in other tissues, such as teeth and bone, might be more informative about long-term exposure and chronic effects on health, large-scale sampling of them has seldom been achieved. However, Needleman et al. (1979) measured long-term exposure of children to lead by analysing teeth, and the recent use of X-ray fluorescence for measuring bone lead may also make such studies more practical (Specht et al. 2019). Hence, much of what is known about the health effects of lead is based upon correlations between health outcomes and $\mathrm{B}-\mathrm{Pb}$.

The consequences for human health of exposure to lead from many sources have been considered in great detail by the appropriate authorities of several countries. Lead affects the nervous, urinary, cardiovascular, immune, reproductive and other body systems and a range of organs, including the brain (USATSDR 2007; EFSA 2010). Experiments show that high doses of lead can induce tumours in rodents, and possibly humans, and the International Agency for Research on Cancer classified inorganic lead as 'probably carcinogenic to humans' (Group 2A) in 2006 (IARC 2006). Body systems particularly sensitive to low levels of exposure to lead include the hematopoietic, nervous, cardiovascular and renal systems (EFSA 2010).

Green and Pain (2012) used a statistical model fitted by Borja-Aburto et al. (1999) to describe the relationship between $\mathrm{B}-\mathrm{Pb}$ and the proportion of pregnant women in Mexico City who incurred spontaneous abortion. The model adjusted for the effect of a previous history of spontaneous abortion. EFSA (2010) did not evaluate this study, which indicated an increased risk of spontaneous abortion for women with high $\mathrm{B}-\mathrm{Pb}$ levels.

The effects of lead on the developing nervous system appear to persist to influence the academic performance of children of school age. In a study published too late to be assessed by the EFSA CONTAM Panel, Chandramouli et al. (2009) reported a marked negative association of academic test results of UK schoolchildren at Key Stage 1 (SATs tests) with B-Pb measured at 30 months of age. To define a change in SATs KS1 writing score equivalent to that of 1 IQ point, identified as the BMR for IQ by EFSA (2010), Green and Pain (2015b) first obtained the maximum-likelihood mean and standard deviation of SATs scores for children in England in 2010 (Department for Education 2013). They then divided this value by 15 (because the standard deviation of population IQ is 15) to obtain the BMR for the SATs KS1 writing grade score. They estimated that, in a typical year, thousands to tens of thousands of children in the UK are consuming sufficient quantities of game shot with lead ammunition for the effect to exceed this BMR level.

Persistent effects of lead on cognitive function over even longer periods were reported by Reuben et al. (2017) in New Zealand. They related IQ measured at age 38 years to $\mathrm{B}-\mathrm{Pb}$ measured at 11 years. After adjusting statistically for effects of maternal IQ, childhood IQ, and childhood socioeconomic status, each $5-\mu \mathrm{g} / \mathrm{dL}$ increment in $\mathrm{B}-\mathrm{Pb}$ in childhood was associated with a reduction in IQ at 38 years old of 1.61 points. Thus, they found not just an association between greater blood lead levels in childhood and adult IQ, but also with a decline in IQ from childhood to adulthood.

\section{Changes in approach to the evaluation of risks from chronic low-level exposure to lead}

In recent decades, public health authorities have made fundamental changes in their approach to the identification 
of tolerable rates of exposure to dietary lead. Up to the 1990 s, it was assumed that there were levels of exposure to lead that would not give rise to significant adverse effects on health, but this was followed by increasing recognition that thresholds below which exposure was safe could not be determined. These developments are summarised in Table 1.

Based on an analysis of the extensive existing information, EFSA (2010) proposed that approaches that assumed the existence of safe thresholds should be replaced by the use of the Benchmark Dose (BMD) approach. The BMD is the $\mathrm{B}-\mathrm{Pb}$ concentration associated with a pre-specified change in response (i.e. a specified loss of IQ, increase in systolic blood pressure, increased incidence of chronic kidney disease), the Benchmark Response (BMR). EFSA (2010) proposed BMRs that could have significant consequences for human health on a population basis as a one point (1\%) reduction in IQ, a $1 \%$ increase in systolic blood pressure (SBP) (equivalent to a $1.2 \mathrm{mmHg}$ change), and a $10 \%$ increase in expected incidence of chronic kidney disease (CKD) as the BMR for nephrotoxicity (EFSA 2010). EFSA (2010) also proposed that significant levels of exposure should be set using Benchmark Dose Limit (BMDL) reference points, which take into account statistical uncertainty in the determination of BMDs.

Although relevant agencies have determined that there are no currently defined thresholds for lead intake below which there are expected to be no negative effects on health, there remains a tendency to treat some exposure levels below those expected to cause the BMR as "essentially negligible". However, as Wilson and Richardson (2013) comment, this "is a matter of regulatory policy, not science". In our view, the implied acceptance of avoidable and quantifiable negative effects on health is undesirable.

\section{HAZARDS TO HUMAN HEALTH FROM AMMUNITION-DERIVED DIETARY LEAD IN EUROPE}

EFSA (2010) used information on lead concentrations in food and amounts of food eaten by individuals in 19 participating countries to calculate mean ('average base diet') and 95th percentile ('high base diet') lead dietary exposures separately for each country. These data were presented as ranges, from the country with the lowest average exposure to that with the highest average exposure. These exposure data were then used to estimate corresponding $\mathrm{B}-\mathrm{Pb}$ concentrations, and these were compared with Bench Mark Doses, adjusted for uncertainty (BMDLs) to evaluate risk (Table 2). Adults, but not children, frequently consuming game meat (defined as one $200 \mathrm{~g}$ meal per week of game) were considered separately for average base diet consumers, but not for high base diet consumers. In calculating the effects upon $\mathrm{B}-\mathrm{Pb}$ of game meat consumption the EFSA (2010) assumed that the bioavailability of dietary lead directly derived from ammunition was the same as for other sources of dietary lead. They obtained the ratio of dietary exposure, assuming various diets, to the BMDLs. The risk of Benchmark Responses occurring was considered to be of particular concern if this ratio exceeded one. EFSA (2010) concluded that there was a potential risk that some children in groups with average and high base diets could incur reductions of one IQ point as a result of exposure to dietary lead. Exposure to additional lead from frequent consumption of game, while not specifically evaluated, would further increase this risk in those exposed. EFSA (2010) concluded that risk of cardiovascular effects as a result of exposure to dietary lead was very low for adult average consumers across European countries. However, if exposure to dietary lead was closer to the upper end of the range in adult high consumers, the potential exists for some consumers to have increased systolic blood pressure as a result of exposure to lead. For nephrotoxicity, EFSA (2010) concluded that it is possible some consumers of an average base diet at the high end of the exposure range, and of consumers of a high base diet across the exposure ranges could potentially incur chronic kidney disease as a result of exposure to dietary lead. For consumers of an average base-diet, but also with frequent consumption of game meat, EFSA (2010) concluded that there was a risk that some people could incur cardiovascular and nephrotoxic effects as a result of exposure to lead. In summary, EFSA (2010) concluded that, at current levels of dietary lead exposure, there is only a low to negligible risk of clinically important effects on either the cardiovascular system or kidneys of adult consumers, for the population in general. However, the results indicate that groups of adults who are frequent consumers of game are at increased risk of suffering clinically important effects. There is also concern about possible effects on neurodevelopment at current levels of exposure to lead for infants, children and pregnant women. The effects of frequent consumption of game shot with lead ammunition was not specifically studied for these most vulnerable groups, but would be expected to further increase exposure and risk.

Green and Pain (2015b) estimated numbers of people in the UK in at-risk groups expected to have intake rates of ammunition-derived dietary lead that would result in effects exceeding the EFSA (2010) BMR levels. They used data on lead concentrations in UK gamebirds, from which gunshot had been removed following cooking to simulate human exposure to lead (Pain et al. 2010), in combination with UK national diet survey data and surveys of numbers of high-level consumers of game meat and their levels of 
Table 1 Evidence-based changes in the approach to the evaluation of risks from chronic low-level exposure to lead

\begin{tabular}{|c|c|}
\hline Event & References \\
\hline $\begin{array}{l}\text { Public health authorities formerly identified a tolerable rate of dietary intake of lead intended to maintain } \\
\text { exposure below an assumed no-observed-adverse-effect-level (NOAEL). An example is the } \\
\text { Provisional Tolerable Weekly Intake (PTWI) of lead for infants and children set by the World Health } \\
\text { Organization Joint Expert Committee on Food Additives and Contaminants (JECFA) in 1982. The } \\
\text { PTWI approach was endorsed by the EU Commission's Scientific Committee on Food. In the EU, this } \\
\text { approach, together with data on lead exposure, resulted in the setting of Maximum Levels of lead in } \\
\text { many foodstuffs in the EU Regulation (EC) No 1881/2006 }\end{array}$ & SCF (1994), SCOOP (2004) \\
\hline $\begin{array}{l}\text { The U.S. Environmental Protection Agency, California EPA and World Health Organization concluded } \\
\text { that lead is a substance for which a threshold level for negative effects on human health cannot } \\
\text { currently be determined. This rendered the NOAEL and PTWI approaches suspect }\end{array}$ & $\begin{array}{l}\text { USEPA (2006), CalEPA } \\
\quad(1997,2009), \text { WHO (2009) }\end{array}$ \\
\hline $\begin{array}{l}\text { The European Commission requested the European Food Safety Authority (EFSA) to produce a scientific } \\
\text { opinion on the risks to human health related to the presence of lead in foodstuffs including to consider } \\
\text { whether the PTWI of } 25 \mu \mathrm{g} / \mathrm{kg} \text { b.w. was still appropriate }\end{array}$ & EFSA (2010) \\
\hline $\begin{array}{l}\text { The EFSA CONTAM Panel identified developmental neurotoxicity in young children and cardiovascular } \\
\text { effects and nephrotoxicity in adults as the critical effects for the risk assessment }\end{array}$ & EFSA (2010) \\
\hline $\begin{array}{l}\text { A meta-analysis of the results of seven studies published between } 1989 \text { and } 2003 \text { of the IQ of } 1333 \\
\text { children in relation to } \mathrm{B}-\mathrm{Pb} \text {, and a refinement/reanalysis of the same data found marked decreases in IQ } \\
\text { with increasing } \mathrm{B}-\mathrm{Pb} \text {, even at low B-Pb values. }\end{array}$ & $\begin{array}{l}\text { Lanphear et al. (2005), Budtz- } \\
\text { Jørgensen (2010), EFSA (2010) }\end{array}$ \\
\hline $\begin{array}{l}\text { Meta-analyses supported a relatively weak, but statistically significant, association between } \mathrm{B}-\mathrm{Pb} \text { levels } \\
\text { and systolic blood pressure, amounting to an increase in systolic blood pressure of approximately } \\
1 \mathrm{mmHg} \text { with each doubling of } \mathrm{B}-\mathrm{Pb} \text { without any clearly identifiable } \mathrm{B}-\mathrm{Pb} \text { threshold for this effect }\end{array}$ & $\begin{array}{l}\text { Staessen et al. (1994), Nawrot et al. } \\
\quad(2002) \\
\text { EFSA (2010) }\end{array}$ \\
\hline $\begin{array}{l}\text { A range of cross-sectional and prospective longitudinal studies were conducted to examine the } \\
\text { relationship between serum creatinine levels, which rise when kidney filtration is deficient, and B-Pb. } \\
\text { Studies suggest an increased likelihood of chronic kidney disease as B-Pb levels rise. EFSA CONTAM } \\
\text { Panel concluded that nephrotoxic effects are real, that they may be greater in men than women and that } \\
\text { they are exacerbated by concurrent diabetes or hypertension }\end{array}$ & EFSA (2010) \\
\hline $\begin{array}{l}\text { EFSA (2010) concluded that there is no evidence for a minimum B-Pb threshold below which effects on } \\
\text { IQ, systolic blood pressure and chronic kidney disease do not occur. Hence, they considered that the } \\
\text { NOAEL and PTWI approaches were not supported by evidence }\end{array}$ & EFSA (2010) \\
\hline $\begin{array}{l}\text { Abandonment of NOAEL and PTWI approaches by EFSA was followed by similar conclusions by the } \\
\text { WHO/FAO JECFA, Health Canada, and the Centers for Disease Control and Prevention in the United } \\
\text { States }\end{array}$ & $\begin{array}{l}\text { JECFA (2011), Health Canada } \\
\text { (2012), ACCLPP (2012) }\end{array}$ \\
\hline
\end{tabular}

consumption. They found that at least one million people in the UK consume wild game at least once per year and surveys indicate that at least tens of thousands of people from the shooting community are high-level consumers of wild-shot game. The mean frequency of consumption of game meat by these high-level consumers may exceed one game meat meal per week, averaged over a whole year. It was estimated that thousands of children in the UK (calculated to be in the range 4000-48 000) were at potential risk of incurring a one point or more reduction in IQ as a result of current levels of exposure to ammunition-derived dietary lead. Numbers of adults potentially vulnerable to critical health effects appear to be smaller, but the available data are too sparse to be certain.

No detailed studies have been conducted across the EU or Europe to evaluate the numbers of children or adults at risk of negative health effects caused by ingested lead ammunition, but an approximate indication of possible numbers can be obtained. EFSA defined 'high-level consumers' of game meat as adults who eat an average of at least one $200 \mathrm{~g}$ meal of game meat per week. Weights of meals vary as will lead exposure depending upon the type of meal (gamebird or large game). While the amount of wild game consumed in all EU countries is not known, Pain et al. (2019), proposed an approximate estimate for children by scaling the number of UK children exposed to high dietary levels of ammunition-derived lead (c. 10 000) by the number of hunters in other EU countries, relative to numbers in the UK. The main assumption of this approach is that overall per capita game consumption by hunters and their families is fairly consistent across EU countries and is similar, on average, to the level found in the UK. Based on these assumptions, it was estimated that 83000 or more children across the EU27 may be at risk of a reduction in IQ of 1 point.

Green and Pain (2015b) also used UK National Diet and Nutrition Survey (NDNS) data to estimate the total number of people estimated to consume gamebird meat in a typical 4-day period, averaged over the whole year. This was $2.52 \%$ of the UK population (95\% CL 2.02-3.01\%). This 
Table 2 Daily dietary lead intake values across the EU and lead intake values corresponding to blood lead levels associated with Benchmark Dose Limit reference points for effects on IQ, Systolic Blood Pressure and Chronic Kidney Disease. Taken from EFSA (2010)

\begin{tabular}{|c|c|c|}
\hline BMDL & $\begin{array}{l}\text { Blood lead } \\
(\mu \mathrm{g} / \mathrm{L})\end{array}$ & $\begin{array}{l}\text { Lead intake } \\
(\mu \mathrm{g} / \mathrm{kg} \text { b.w./d) }\end{array}$ \\
\hline $\mathrm{IQ}-\mathrm{BMDL}_{01}$ & 12 & 0.50 \\
\hline $\mathrm{SBP}-\mathrm{BMDL}_{01}$ & 36 & 1.50 \\
\hline $\mathrm{CKD}-\mathrm{BMDL}_{10}$ & 15 & 0.63 \\
\hline \multicolumn{3}{|l|}{$\begin{array}{l}\text { Daily lead intake across EU } \\
\text { participating countries } \mu \mathrm{g} / \mathrm{kg} \text { b.w./d }\end{array}$} \\
\hline Adults, average base diet & & $0.36-1.24$ \\
\hline Adults, average base diet with game & & $1.98-2.44$ \\
\hline Adults, high base diet & & $0.73-2.43$ \\
\hline Children, average base diet & & $0.80-3.10$ \\
\hline Children, high base diet & & $1.71-5.51$ \\
\hline
\end{tabular}

The BMDL is the 95th percentile lower confidence limit of the benchmark dose (BMD) of $1 \%$ extra risk $\left(\mathrm{BMDL}_{01}\right)$ used as a reference point for the risk characterisation of lead when assessing the risk of intellectual deficits in children measured by the Full Scale IQ score (1 IQ point reduction) or a $1 \%$ increase in systolic blood pressure (SBP). For chronic kidney disease, the BMDL 10 represents a $10 \%$ increase in prevalence

rate may be representative of the situation at any time of year as proportions of people eating gamebird meat appear to be similar within and outside the hunting season (Taylor et al. 2014). To consider an extreme assumption: if the same people eat gamebird meals consistently in every 4-day period throughout the year then over $2.52 \%$ of the population would eat at least one gamebird meal per week, averaged across the year. At the opposite extreme, if people who eat gamebird meat only do so occasionally, then a higher proportion of the population will eat gamebirds but with a lower frequency. The most extreme case of this kind that would yield the same mean rate of gamebird consumption per 4-day period observed in the diet survey would be if $90.3 \%$ of the UK population ate just one gamebird meal per year. However, we can be sure that this hypothetical uniform low level of game consumption is not the case. A survey of members of the shooting community in the UK, conducted by the British Association for Shooting and Conservation (BASC) and the Countryside Alliance (CA), estimated that about 9000 (midpoint of the range 5500-12 500) children under 8 years old and about 44500 adults (midpoint of the range 27 000-62 000) from that community consume at least one game meal per week, averaged over the whole year, with all types of game being included (cited in LAG 2014). These 53500 adults and children from the shooting community represent $0.084 \%$ of the UK population. The percentage of high level consumers of game in the UK would, therefore, appear to lie between $0.084 \%$ and $2.52 \%$ of the population.

In Italy, Ferri et al. (2017) used questionnaire surveys to study game consumption by 766 Italian shooters. An average of 100-200 g game per serving was consumed with an average of four servings per month (once per week). The highest rate of game intake recorded was $3 \mathrm{~kg}$ per month, and game was regularly consumed with friends and relatives. From these results, it was estimated that $3 \%$ of the Italian population were regular consumers of wild game. Danieli et al. (2012) found that hunters and their families in central Italy ( 221 adults and 41 children) regularly ate wild boar throughout the year with mean weekly consumption of $123 \mathrm{~g}$ meat, $45 \mathrm{~g}$ liver by adults, and $49 \mathrm{~g}$ meat, $10 \mathrm{~g}$ liver by children. 80 adults and 18 children ate both meat and liver.

In Spain, $6.3 \%$ of 3000 people surveyed reported eating game meat of all kinds (large game, partridge, quail or rabbit), but the frequency of consumption was not given (AESAN 2012). In a separate study of people that reported eating game, Sevillano Morales et al. (2011) found that average consumption of red deer and wild boar, in people that consumed both meats, was $8.4 \mathrm{~kg} /$ year (maximum $56.67 \mathrm{~kg} /$ year) for hunters $(n=90)$ and $4.41(\max .55 \mathrm{~kg} /$ year) in non-hunters $(n=50)$. Maximum consumption was by two people who only ate large game meat, so represents an outlying extreme. Sevillano Morales et al. (2018) found mean game meat consumption of $8.57 \mathrm{~kg} /$ person/year (of wild boar, red deer, rabbit (Oryctolagus cuniculus), partridge (Alectoris rufa) and processed meat products made from them) in 337 habitual consumers of game (hunters and their relatives).

In Germany, Gerofke et al. (2018) conducted a game consumption survey of a representative sample of 1000 people and found that the minimum proportion of people that consumed meals of at least one of either red deer, roe deer and wild boar was: more than once per week $(0.8 \%)$; once per week $(0.7 \%)$; one to 3 times per month $(2.4 \%)$; 6-11 times per year (2.3\%); one to 5 times per year $(31.9 \%)$. Game consumption figures for the three species were given separately and the authors do not state whether those people that ate one species also ate other species. Hence these rates are minima.

No reliable data exist on the amounts of game consumed in France, but ANSES (2018) performed a risk assessment in which most consumers of game were considered to be hunters and their relatives. Since 1.1 million people have a hunting permit, a total of about 3-4 million people were thought to consume game. This comprises about $6 \%$ of the population. Among these, two scenarios of game consumption were considered, those of regular (e.g. $200 \mathrm{~g}$ every 2 weeks) or high ( $200 \mathrm{~g}$ per week) consumption. 
Sweden has an annual "production" of game meat corresponding to approximately $12 \%$ of the production of beef, and about 600 000-900 000 persons (7-10\% of the population) were estimated to be potential high consumers of game, though there was no definition of a high rate of consumption (Ankarberg et al. 2013).

Taken as a whole, the studies described above indicate that the main consumers of game are hunters and their families and associates, and that a few percent of the population may be frequent (a few times per month) or high (once per week or more) consumers of game in most countries. While we have only been able to find any kind of estimate or assumed consumption levels for six countries, these countries hold more than two-thirds (67\%) of all EU hunters (FACE 2010) and include the five countries with the most hunters, i.e. France, Spain, UK, Italy and Germany. Consequently they are likely to be broadly representative of the EU and illustrate that the number of people at potential risk of health effects from lead in game is nonnegligible across the EU. Taking the consumption of at least one meal of game meat per week, averaged across the whole year, as the definition of a high-level game consumer, and assuming that $1 \%$ of the total population of the EU countries are high-level consumers, gives a rough estimate of about 5 million high-level consumers in the EU.

In accord with these conclusions, the UK Food Standards Agency (FSA 2012) have advised that frequent consumers of game shot with lead ammunition should eat less of this type of meat, and that this is especially important in the case of toddlers and children, pregnant women and women trying for a baby, because of the harm that lead can cause to the brain and developing nervous system. The FSA does not recommend any lower level of consumption as being safe for these at-risk groups. This is similar to recent advice given following risk assessments by equivalent agencies in a range of other European countries who consider that these most vulnerable groups should eat little or no game shot with lead ammunition (AESAN 2012; Knutsen et al. 2015; ANSES 2018; Gerofke et al. 2018). The risks to vulnerable groups such as frequent consumers, women of childbearing age especially who are pregnant or trying to become pregnant, and children from eating game shot with lead, are acknowledged by FACE, the European Federation for Hunting and Conservation, which is the international organisation set up in 1977 to represent the interests of European game hunters. FACE recommend that women who are pregnant or planning to get pregnant and children $<7$ years should avoid eating lead-contaminated meat (FACE 2018). FACE suggest that these groups can reduce their risk by eating game killed using non-lead ammunition, removing lead fragments by sufficient cleaning or consuming less game. However, consumption of less game shot using lead ammunition does not constitute the avoidance that FACE recommend. For reasons we explain in an earlier section, we are also sceptical, from the evidence available so far, that practical methods for preparing the meat of small game would achieve the avoidance of ingestion of lead-contaminated meat. We suggest that avoidance of any game, avoidance of game shot with lead ammunition, and only consuming game killed using non-lead ammunition are the practical methods by which at-risk groups can achieve the avoidance of lead-contaminated meat recommended by FACE.

While our review focuses on risks from exposure to ammunition lead in Europe, these risks are present anywhere where people frequently consume wild game shot with lead ammunition. Game consumption levels may vary between countries, and include everything from bushmeat harvested with lead (e.g. in Benin, Ahmadi et al. 2018) to extreme cases where individuals subsist almost exclusively on self-killed game (e.g. a case study of a hunter in New Zealand, Buenz and Parry 2017).

\section{WIDER CONSEQUENCES OF AMMUNITION- DERIVED DIETARY LEAD FOR HUMAN HEALTH AND WELL-BEING}

As more information becomes available from long-term studies, there is increasing evidence of effects on human health and well-being of low-level environmental lead exposure, and these have implications for exposure from any source. For example, Lanphear et al. (2018), in a study of $>14000$ adults, found that an increase in $\mathrm{B}-\mathrm{Pb}$ from 1.0 to $6.7 \mu \mathrm{g} / \mathrm{dL}$ was associated with mortality from cardiovascular disease and ischaemic heart disease. The authors concluded that low-level lead exposure is an important, and largely overlooked, risk factor for cardiovascular disease mortality in the USA.

In addition to the health effects and lack of attainment probably experienced by individuals as a result of frequent exposure to ammunition-derived dietary lead, there are likely to be consequences for societies which are felt more widely. Additional ill-health caused by dietary lead results in additional costs and burdens for health services and taxpayers. More difficult to assess are effects on society mediated through effects of exposure to lead on human behaviour, including antisocial and criminal behaviour. In the twentieth century, there were large changes in exposure of humans to environmental lead caused by the introduction of regulations to reduce or prevent the use of lead in products, especially leaded petrol. These regulations differed geographically in timing and scope, thus constituting a set of uncontrolled natural experiments on the effects of changes in exposure to environmental lead on human 
behaviour. Nevin (2007) reported an association between preschool blood lead levels in the USA, Britain, Canada, France, Australia, Finland, Italy, West Germany, and New Zealand and subsequent trends in rates of crime, arrest and incarceration. These observations were most consistent with effects of exposure to lead causing neurobehavioral damage in the first year of life. Reyes (2015) analysed the association of early childhood lead exposure with antisocial behaviour problems from childhood into early adulthood for two cohorts of children in the USA and found marked effects. A prospective longitudinal study found significant relationships between prenatal and postnatal exposure of children to lead, determined by blood sampling, and covariate-adjusted rates of self- and parent-reported antisocial and delinquent behaviours later in life (Dietrich et al. 2001). Boutwell et al. (2017) conducted a correlational study in St Louis, USA, in which they examined the association of geographical variation among regions of the city (called 'census tracts') in lead exposure (from $\mathrm{B}-\mathrm{Pb}$ measurements) and various indicators of criminal and antisocial behaviour. The study B-Pb levels were statistically significant predictors of the incidence of firearm crimes, assault, robbery and homicide, even after accounting for important sociological variables. However, they found no significant association between $\mathrm{B}-\mathrm{Pb}$ and the incidence of rape.

At a population level, the differences and changes in $\mathrm{B}-\mathrm{Pb}$ examined in these studies of the links between lead exposure and crime, which resulted largely from differences and changes in exposure to leaded petrol, were large compared with those expected to be caused by reducing exposure to ammunition-derived lead. Nonetheless, the possible consequences for groups currently exposed to this toxic dietary contaminant should not be ignored.

Acknowledgements The authors wish to thank John Swift and other colleagues of the Lead Ammunition Group for discussions.

Open Access This article is distributed under the terms of the Creative Commons Attribution 4.0 International License (http:// creativecommons.org/licenses/by/4.0/), which permits unrestricted use, distribution, and reproduction in any medium, provided you give appropriate credit to the original author(s) and the source, provide a link to the Creative Commons license, and indicate if changes were made.

\section{REFERENCES}

ACCLPP. 2012. Low level lead exposure harms children: A renewed call for primary prevention. Report of the Advisory Committee on Childhood Lead Poisoning Prevention of the Centres for Disease Control and Prevention. Retrieved 07 February, 2019, from http://www.cdc.gov/nceh/lead/ACCLPP/Final_Document_ 030712.pdf.
AESAN. 2012. Report of the Scientific Committee of the Spanish Agency for Food Safety and Nutrition (AESAN) in relation to the risk associated with the presence of lead in wild game meat in Spain. AESAN-2012-002. Report approved by the Scientific Committee on plenary session, February 22, 2012. http://aesan. msssi.gob.es/AESAN/docs/docs/evaluacion_riesgos/comite_ cientifico/PLOMO_CAZA.pdf.

Ahmadi, S., S. Maman, R. Zoumenou, A. Massougbodji, M. Cot, P. Glorennec, and F. Bodeau-Livinec. 2018. Hunting, sale, and consumption of bushmeat killed by lead-based ammunition in Benin. International Journal of Environmental Research and Public Health 15: 1140. https://doi.org/10.3390/ijerph15061140.

Andreotti, A., and F. Borghesi. 2013. Embedded lead shot in European starlings Sturnus vulgaris: An underestimated hazard for humans and birds of prey. European Journal of Wildlife Research 59: 705-712. https://doi.org/10.1007/s10344-0130725-8.

Andreotti, A., F. Borghesi, and A. Aradis. 2016. Lead ammunition residues in the meat of hunted woodcock: A potential health risk to consumers. Italian Journal of Animal Science 15: 22-29. https://doi.org/10.1080/1828051X.2016.1142360.

Ankarberg, E.H., R. Bjerselius, B. Kollander, S. Sand, K. Scherling, C. Linné, F. Widemo, and E. Ågren. 2013. Lead in game in Sweden. Präsentation vom 18. März 2013. Livsvedelsmerket (National Food Agency). Retrieved January 21, 2019, from https://mobil.bfr.bund.de/cm/343/lead-in-game-in-sweden.pdf.

ANSES. 2018. AVIS de l'Agence nationale de sécurité sanitaire de l'alimentation, de l'environnement et du travail relatif au "risque sanitaire lié à la consommation de gibier au regard des contaminants chimiques environnementaux (dioxines, polychlorobiphényles (PCB), cadmium et plomb)". Avis de l'ANSES Saisine No. 2015-SA-0109. ANSES, Maisons-Alfort Cedex. Retrieved January 2019, from https://www.anses.fr/ $\mathrm{fr} /$ content/consommation-de-gibier-sauvage-agir-pour-r\%C3\% A9duire-les-expositions-aux-contaminants-chimiques.

Barltrop, D., and F. Meek. 1975. Absorption of different lead compounds. Postgraduate Medical Journal 51: 805-809.

Bjermo, H., S. Sand, C. Nälsén, T. Lundh, H. Enghardt Barbieri, M. Pearson, A.K. Lindroos, B.A.G. Jönsson, et al. 2013. Lead, mercury, and cadmium in blood and their relation to diet among Swedish adults. Food and Chemical Toxicology 57: 161-169.

Bjerregaard, P., O. Johansen, G. Mulvad, H.S. Pedersen, and J.C. Hansen. 2004. Lead sources in human diet in Greenland. Environmental Health Perspectives 112: 1496-1498.

Borja-Aburto, V.-H., I. Hertz-Picciotto, M. Rojas Lopez, P. Farias, C. Rios, and J. Blanco. 1999. Blood lead levels measured prospectively and risk of spontaneous abortion. American Journal of Epidemiology 150: 590-597.

Boutwell, B.B., E.J. Nelson, Z. Qian, M.G. Vaughn, J.P. Wright, K.M. Beaver, J.C. Barnes, M. Petkovsek, et al. 2017. Aggregatelevel lead exposure, gun violence, homicide, and rape. PLoS ONE 12: e0187953.

Budtz-Jørgensen, E. 2010. An international pooled analysis for obtaining a benchmark dose for 2 environmental lead, exposure in children. Scientific/Technical Report submitted to EFSA. www.efsa.europa.eu.

Buenz, E.J., and G.J. Parry. 2017. Chronic lead intoxication from eating wild-harvested game. American Journal of Medicine 131: e181-e184. https://doi.org/10.1016/j.amjmed.2017.11.031.

CalEPA. 2009. Revised California Human Health Screening Level for Lead (Review Draft). Office of Environmental Health Hazard Assessment, Sacramento, CA. http://www.oehha.ca.gov/risk/pdf/ LeadCHHSL51809.pdf.

CalEPA (California Environmental Protection Agency). 1997. Technical Support Document-proposed identification of inorganic lead as a toxic air contaminant, Part B: Health Assessment. 
CalEPA, Air Resources Board, Sacramento, CA. http://www.arb. ca.gov/toxics/lead/tsdb.pdf.

Carlisle, J.C., and M.J. Wade. 1992. Predicting blood lead concentrations from environmental concentrations. Regulatory Toxicology and Pharmacology 16: 280-289.

Chandramouli, L., C.D. Steer, M. Ellis, and A.M. Emond. 2009. Effects of early childhood lead exposure on academic performance and behaviour of school age children. Archives of Diseases in Childhood 94: 844-848.

Clemente, N., A. Sartori, and M. De Luca. 2017. An unusual case of acute appendicitis. Chirurgia-Italy 30: 18-20.

Codex Alimentarius. 2004. Code of Practice for the prevention and reduction of lead contamination in foods. CAC/RCP 56-2004. http://www.codexalimentarius.org/standards/list-of-standards/.

Codex Alimentarius. 2018. General standard for contaminants and toxins in food and feed CXS 193-1995. Adopted in 1995. Revised in 1997, 2006, 2008, 2009. Amended in 2010, 2012, 2013, 2014, 2015, 2016, 2017, 2018. Rome: Food and Agriculture Organisation.

Danieli, P.P., F. Serranin, R. Primi, M.P. Ponzetta, B. Ronchi, and A. Amici. 2012. Cadmium, lead, and chromium in large game: A local-scale exposure assessment for hunters consuming meat and liver of wild boar. Archives of Environmental Contamination and Toxicology 63: 612-627. https://doi.org/10.1007/s00244012-9791-2.

Department for Education. 2013. National curriculum assessments at key stage 1 in England-academic year 2009 to 2010 (provisional). Accessed August 2015, from https://www.gov.uk/ government/statistics/national-curriculum-assessments-at-keystage-1-in-england-academic-year-2009-to-2010-provisional.

Dewailly, E., P. Ayotte, S. Bruneau, G. Lebel, P. Levallois, and J.P. Weber. 2001. Exposure of the inuit population of Nunavik (Arctic Quebec) to lead and mercury. Archives of Environmental Health 56: 350-357.

Dietrich, K.N., R.M. Douglas, P.A. Succopa, O.G. Berger, and R.L. Bornschein. 2001. Early exposure to lead and juvenile delinquency. Neurotoxicology and Teratology 23: 511-518.

Dobrowolska, A., and M. Melosik. 2008. Bullet-derived lead in tissues of the wild boar (Sus scrofa) and red deer (Cervus elaphus). European Journal of Wildlife Research 54: 231-235.

EC. 2006. European Commission Regulation EC 1881/2006. Setting maximum levels for certain contaminants in foodstuffs. Official Journal of the European Union EC 1881/2006(20.12.2006), L364/365-L364/324. http://eur-lex.europa.eu/legal-content/EN/ TXT/?qid=1442063437890\&uri=CELEX:32006R1881.

EFSA. 2010. Scientific opinion on lead in food. EFSA Panel on Contaminants in the Food Chain (CONTAM). EFSA Journal 8(4), 1570. https://doi.org/10.2903/j.efsa.2010.1570. Updated 22 March 2013, replacing the earlier version published on 20 April 2010. https://doi.org/10.2903/j.efsa.2010.1570.

FACE. 2010. Hunters in Europe in FACE Annual Report 2009-2010.

FACE. 2018. Lead ammunition in game meat. Retrieved February, 2019, from https://www.leadammunitionguidance.com/leadammunition-in-game-meat/.

Ferri, M., L. Baldi, S. Cavallo, R. Pellicanò, and G. Brambilla. 2017. Wild game consumption habits among Italian shooters: Relevance for intakes of cadmium, perfluorooctanesulphonic acid, and 137 Cesium as priority contaminants. Food Additives and Contaminants: Part A. 34: 832-841. https://doi.org/10.1080/ 19440049.2017.1293303.

Finney, M.A., S.S. McAllister, T.B. Maynard, and I.J. Grob. 2016. A study of wildfire ignition by rifle bullets. Fire Technology 52: 931-954.

FSA. 2012 Risk to human health from exposure to lead from lead bullets and shot used to shoot wild game animals. Food Standards Agency.
Fustinoni, S., S. Sucato, D. Consonni, P.M. Mannucci, and A. Moretto. 2017. Blood lead levels following consumption of game meat in Italy. Environmental Research 155: 36-41.

Gerofke, A., E. Ulbig, A. Martin, C. Müller-Graf, T. Selhorst, C. Gremse, M. Spolders, H. Schafft, et al. 2018. Lead content in wild game shot with lead or non-lead ammunition: Does state of the art consumer health protection require non-lead ammunition? PLoS ONE 13: e0200792. https://doi.org/10.1371/journal.pone. 0200792.

Green, P. 2015. The risks to human health through livestock feeding in areas of lead shot deposition. Appendix 2, pages 149-180 of "Lead Ammunition, Wildlife and Human Health" A report prepared by the Lead Ammunition Group (2 June 2015) for the Department for Environment, Food and Rural Affairs and the Food Standards Agency in the United Kingdom. Retrieved January 21, 2019, from http://www. leadammunitiongroup.org.uk/wp-content/uploads/2015/06/LAGReport-June-2015-Appendices-without-Appendix-6.pdf.

Green, R.E., and D.J. Pain. 2012. Potential health risks to adults and children in the UK from exposure to dietary lead in gamebirds shot with lead ammunition. Food and Chemical Toxicology 50: 4180-4190.

Green, R.E., and D.J. Pain. 2015a. An evaluation of the risks to human health in the UK from lead derived from ammunition. Appendix 1, pages 93-148 of "Lead Ammunition, Wildlife and Human Health" A report prepared by the Lead Ammunition Group (2 June 2015) for the Department for Environment, Food and Rural Affairs and the Food Standards Agency in the United Kingdom. Retrieved January 21, 2019, from http://www. leadammunitiongroup.org.uk/wp-content/uploads/2015/06/LAGReport-June-2015-Appendices-without-Appendix-6.pdf.

Green, R.E., and D.J. Pain. 2015b. Risks of health effects to humans in the UK from ammunition-derived lead. In Proceedings of the Oxford Lead Symposium. Lead ammunition: Understanding and minimising the risks to human and environmental health, ed. R.J. Delahay and C.J. Spray, 27-43. Oxford: Edward Grey Institute, University of Oxford.

Grund, M.D., L. Corncicelli, L.T. Carlson, and B.A. Butler. 2010. Bullet fragmentation and lead deposition in white-tailed deer and domestic sheep. Human-Wildlife Interactions 4: 257-265.

Haldimann, M., A. Baumgartner, and B. Zimmerli. 2002. Intake of lead from game meat-a risk to consumers' health? European Food Research and Technology 215: 375-379.

Health Canada. 2012. Federal Contaminated Site Risk Assessment in Canada-Part I: Guidance on Human Health Preliminary Quantitative Risk Assessment (PQRA), Version 2.0. Contaminated Sites Division, Ottawa, ON, Canada.

Ertl, K., R. Kitzer, and W. Goessler. 2016. Elemental composition of game meat from Austria. Food Additives and Contaminants: Part B 9: 120-126.

Hunt, W.G., R.T. Watson, J.L. Oaks, C.N. Parish, K.K. Burnham, R.L. Tucker, J.R. Belthoff, and G. Hart. 2009. Lead bullet fragments in venison from rifle-killed deer: Potential for human dietary exposure. PLOS ONE. https://doi.org/10.1371/journal. pone. 0005330 .

IARC. 2006. IARC monographs on the evaluation of carcinogenic risks to humans. Volume 87: Inorganic and organic lead compounds, 473 pp. World Health Organisation, International Agency for Research on Cancer, Lyon, France.

IEUBK. 2010. User's Guide for the Integrated Exposure Uptake Biokinetic Model for Lead in Children (IEUBKwin v1.1 build 11). EPA.

Iqbal, S., W. Blumenthal, C. Kennedy, F.Y. Yip, S. Pickard, W.D. Flanders, K. Loringer, K. Kruger, et al. 2009. Hunting with lead: Association between blood lead levels and wild game consumption. Environmental Research 109: 952-959. 
JECFA. 2011. WHO Food Additive Series: 64-Safety Evaluation of Certain Food Additives and Contaminants. Prepared by the seventy-third meeting of JECFA, Joint FAO/WHO Expert Committee on Food Additives, Geneva, Switzerland. ISBN 9789241660648.

Johansen, P., G. Asmund, and F. Riget. 2004. High human exposure to lead through consumption of birds hunted with lead shot. Environmental Pollution 127: 125-129.

Johansen, P., H.S. Pedersen, G. Asmund, and F. Riget. 2006. Lead shot from hunting as a source of lead in human blood. Environmental Pollution 142: 93-97.

Knott, J., J. Gilbert, D.G. Hoccom, and R.E. Green. 2010. Implications for wildlife and humans of dietary exposure to lead from fragments of lead rifle bullets in deer shot in the UK. Science of the Total Environment 409: 95-99.

Knutsen, H.K., A.L. Brantsæter, J. Alexander, and H.M. Meltzer. 2015. Associations between consumption of large game animals and blood lead levels in humans in Europe: The Norwegian experience. In Proceedings of the Oxford lead symposium. Lead ammunition: Understanding and minimising the risks to human and environmental health, ed. R.J. Delahay and C.J. Spray, 44-50. Oxford: Edward Grey Institute, University of Oxford.

Kollander, B., B. Sundström, F. Widemo, S. Jägareförbundet, and E. Ågren, 2014. Bly i viltkött. Del 1- ammunitionsrester och kemisk analys. Livsmedelsverket (Food Agency Sweden) Rapport 18: 78 pp. ISSN 1104-7089 (in Swedish with English Summary). Retrieved February 07, 2019, from https://www.livsmede lsverket.se/globalassets/publikationsdatabas/rapporter/2014/blyi-viltkott-del-1-ammunitionsrester-och-kemisk-analys.pdf.

Kollander, B., F. Widemo, E. Ågren, E.H. Larsen, and K. Loeschner. 2017. Detection of lead nanoparticles in game meat by single particle ICP-MS following use of lead-containing bullets. Analytical and Bioanalytical Chemistry 409: 1877-1885.

LAG. 2014. Minutes of the 11th Lead Ammunition Group (LAG) meeting-16 April 2014: Agenda item 11.2. Retrieved February 01, 2019, from http://www.leadammunitiongroup.org.uk/wpcontent/uploads/2015/07/LAG_meeting_minutes_11_1600414. pdf.

Lanphear, B.P., R. Hornung, J. Khoury, K. Yolton, P. Baghurst, D.C. Bellinger, R.L. Canfield, K.N. Dietrich, et al. 2005. Low-level environmental lead exposure and children's intellectual function: An international pooled analysis. Environmental Health Perspectives 113: 894-899.

Lanphear, B.P., S. Rauch, P. Auinger, R.W. Allen, and R.W. Hornung. 2018. Low-level lead exposure and mortality in US adults: A population-based cohort study. The Lancet: Public Health 3: e177-e184. https://doi.org/10.1016/S24682667(18)30025-2.

Lehel, J., P. Laczay, A. Gyurcsó, F. Jánoska, S. Majoros, K. Lányi, and M. Marosán. 2016. Toxic heavy metals in the muscle of roe deer (Capreolus capreolus)_food toxicological significance. Environmental Science and Pollution Research International 23: 4465-4472. https://doi.org/10.1007/s11356-015-5658-1.

Lindboe, M., E.N. Henrichsen, H.R. Høgåsen, and A. Bernhoft. 2012. Lead concentration in meat from lead-killed moose and predicted human exposure using Monte Carlo simulation. Food Additives and Contaminants: Part A 29: 1052-1057.

McAuley, C., C. Ng, C. McFarland, A. Dersch, B. Koppe, and D. Sowan. 2018. Lead exposure through consumption of small game harvested using lead-based ammunition and the corresponding health risks to first nations in Alberta. Canada: Cogent Environmental Science. https://doi.org/10.1080/23311843.2018. 1557316.

Meltzer, H.M., H. Dahl, A.L. Brantsæter, B.E. Birgisdottir, H.K. Knutsen, A. Bernhoft, B. Oftedal, U.S. Lande, et al. 2013. Consumption of lead-shot cervid meat and blood lead concentrations in a group of adult Norwegians. Environmental Research 127: 29-39.

Mushak, P. 1998. Uses and limits of empirical data in measuring and modeling human lead exposure. Environmental Health Perspectives 106: 1467-1484.

Nawrot, T.S., L. Thijs, E.M. Den Hond, H.A. Roels, and J.A. Staessen. 2002. An epidemiological reappraisal of the association between blood pressure and blood lead: A meta-analysis. Journal of Human Hypertension 16: 123-131.

Needleman, H.L., C. Gunnoe, A. Leviton, R. Reed, H. Peresie, C. Maher, and P. Barrett. 1979. Deficits in psychologic and classroom performance of children with elevated dentine lead levels. New England Journal of Medicine 300: 689-695.

Nevin, R. 2007. Understanding international crime trends: The legacy of preschool lead exposure. Environmental Research 104: 315-336.

Oomen, A.G., J. Tolls, A.J. Sips, and J.P. Groten. 2003. In vitro intestinal lead uptake and transport in relation to speciation. Archives of Environmental Contamination and Toxicology 44: 116-124.

Pain, D.J., R.L. Cromie, J. Newth, M.J. Brown, E. Crutcher, P. Hardman, L. Hurst, R. Mateo, et al. 2010. Potential hazard to human health from exposure to fragments of lead bullets and shot in the tissues of game animals. PLOS ONE 5: e10315. https://doi.org/10.1371/journal.pone.0010315.

Pain, D.J., I. Dickie, R.E. Green, N. Kanstrup, and R. Cromie. 2019. Wildlife, human and environmental costs of using lead ammunition: An economic review and analysis. In Lead in hunting ammunition: Persistent problems and solutions, eds. N. Kanstrup, V.G. Thomas, and A.D. Fox, Ambio vol. 48, Special Issue. https://doi.org/10.1007/s13280-019-01157-2.

Reuben, A., A. Caspi, D.W. Belsky, J. Broadbent, H. Harrington, K. Sugden, R.M. Houts, S. Ramrakha, et al. 2017. Association of childhood blood lead levels with cognitive function and socioeconomic status at age 38 years and with IQ change and socioeconomic mobility between childhood and adulthood. JAMA 317: 1244-1251.

Reyes, J.W. 2015. Lead exposure and behavior: Effects on antisocial and risky behavior among children and adolescents. Economic Inquiry 53: 1580-1605.

SCF. 1994. European Commission's Scientific Committee for Food (SCF) Opinion of 19 June 1992, Thirty second series, p. 7. http:// ec.europa.eu/food/fs/sc/scf/reports/scf_reports_32.pdf.

SCOOP (Scientific Cooperation). 2004. SCOOP Report of experts participating in Task 3.2.11. March 2004. Assessment of the dietary exposure to arsenic, cadmium, lead and mercury of the population of the EU Member States, $125 \mathrm{pp}$.

Sevillano Morales, J.S., R. Moreno Rojas, F. Pérez-Rodríguez, A. Arenas Casas, and M.A. Amaro López. 2011. Risk assessment of the lead intake by consumption of red deer and wild boar meat in Southern Spain. Food Additives \& Contaminants 28: 1021-1033.

Sevillano Morales, J., A. Moreno-Ortega, M.A. Amaro Lopez, A. Arenas Casas, F. Cámara-Martos, and R. Moreno-Rojas. 2018. Game meat consumption by hunters and their relatives: A probabilistic approach. Food Additives and Contaminants Part A 35: 1739-1748. $\quad$ https://doi.org/10.1080/19440049.2018. 1488183.

Specht, A.J., K.E. Kirchner, M.G. Weisskopf, and M.A. Pokras. 2019. Lead exposure biomarkers in the Common Loon. Science of the Total Environment 647: 639-644. https://doi.org/10.1016/j. scitotenv.2018.08.043.

Staessen, J.A., C.J. Bulpitt, R. Fagard, R.R. Lauwerys, H. Roels, L. Thijs, and A. Amery. 1994. Hypertension caused by low-level lead exposure: Myth or fact? Journal of Cardiovascular Risk 1: 87-97. 
Stankevičiūte, J., P. Pètelis, J. Baranauskaite, and G. Narauskaitè. 2013. Influence of lead shot pellets injury on meat yield of European hare (Lepus europaeus Pallas). In Proceedings of 6th international scientific conference on rural development-innovations and sustainability, vol. 6, 245-249. Akademija, Lithuania, 28-29 November 2013. Retrieved February 01, 2019, from https://www. researchgate.net/profile/Barbara_Sawicka3/publication/263966544_ Quality_Parameters_of_the_Great_Pumpkin_for_Food/links/53c eaaa40cf2fd75bc585574.pdf.

Stokke, S., S. Brainerd, and J.M. Arnemo. 2017. Metal deposition of copper and lead bullets in moose harvested in Fennoscandia. Wildlife Society Bulletin 41: 98-106. https://doi.org/10.1002/ wsb.731.

Taylor, C.M., J. Golding, and A.M. Emond. 2014. Intake of game birds in the UK: Assessment of the contribution to the dietary intake of lead by women of childbearing age and children. Public Health Nutrition 17: 1125-1129.

Tsuji, L.J.S., B.C. Wainman, I.D. Martin, C. Sutherland, J.-P. Weber, P. Dumasd, and E. Nieboerb. 2008. Lead shot contribution to blood lead of First Nations people: The use of lead isotopes to identify the source of exposure. Science of the Total Environment 405: 180-185.

USATSDR (United States Agency for Toxic Substances and Disease Registry). 2007. Toxicological Profile for lead, 1-582. U.S. Department of Health and Human Services. http://www.atsdr. cdc.gov/toxprofiles/tp13.pdf.

USEPA. 2006. National ambient airquality standards: Air quality criteria for lead. http://cfpub.epa.gov/ncea/cfm/recordisplay. cfm?deid=158823.

Vogt, G., and E.A. Tysnes. 2015. Lead in minced beef from Norwegian hunted game, elk (Alces alces). Eurofins Food and Feed Testing Norway AS Moss. Retrieved March 2018, from https://www. mattilsynet.no/mat_og_vann/jakt_og_viltkjott/rapport_lead_in_ minced_beef_from_norwegian_hunted_game_elg.20383/binary/ Rapport:\%20Lead\%20in\%20minced\%20beef\%20from $\% 20$ Norwegian $\% 20$ hunted $\% 20$ game $\% 20$ Elg.

Weiss, D., C.D. Tomasallo, J.G. Meiman, W. Alarcon, N.M. Grabe, K.M. Bisgard, and H.A. Anderson. 2017. Elevated blood lead levels associated with retained bullet fragments-United States,
2003-2012. MMWR-Morbidity and Mortality Weekly Report 66: $130-133$.

WHO. 2009. Levels of lead in children's blood. Factsheet 4.5, European Environment and Health Information System. Retrieved February 7, 2019, from http://www.euro.who.int/ data/assets/pdf_file/0003/97050/4.5.-Levels-of-lead-in-childrensblood-EDITING_layouted.pdf.

Wilson, R., and G.M. Richardson. 2013. Lead $(\mathrm{Pb})$ is now a nonthreshold substance: How does this affect soil quality guidelines? Human and Ecological Risk Assessment: An International Journal 19: 1152-1171. https://doi.org/10.1080/10807039. 2013.771534 .

Publisher's Note Springer Nature remains neutral with regard to jurisdictional claims in published maps and institutional affiliations.

\section{AUTHOR BIOGRAPHIES}

Rhys E. Green $(\varangle)$ is an Honorary Professor of Conservation Science in the Department of Zoology at the University of Cambridge. His research interests include the effects of human activities on population size and demographic rates of wild species. He uses statistical and simulation models fitted to data on these effects to devise practical interventions that land managers can use to reduce negative effects on wild species so as to improve their conservation status.

Address: Department of Zoology, University of Cambridge, David Attenborough Building, Pembroke Street, Cambridge CB2 3QZ, UK. e-mail: reg29@hermes.cam.ac.uk

Deborah J. Pain is an Honorary Research Fellow in the Department of Zoology, University of Cambridge. Her research interests include diagnosing the causes of declines in threatened bird species and developing and testing practical and policy solutions to reverse them. She has interest in ecotoxicology, particularly lead poisoning from ammunition, on which she has worked since the early 1980s.

Address: Department of Zoology, University of Cambridge, David Attenborough Building, Pembroke Street, Cambridge CB2 3QZ, UK. e-mail: pain.debbie@gmail.com 